\title{
Creating chemo- and bioinformatics workflows, further developments within the CDK-Taverna Project
} T Kuhn*1,2, A Zielesny ${ }^{2}$ and C Steinbeck ${ }^{3}$

Address: ${ }^{1}$ Cologne University Bioinformatics Center (CUBIC), Cologne, Germany, ${ }^{2}$ University of Applied Sciences of Gelsenkirchen, Institute for Bioinformatics and Chemoinformatics, Recklinghausen, Germany and ${ }^{3}$ European Bioinformatics Institute (EBI), Cambridge, UK

* Corresponding author

from 4th German Conference on Chemoinformatics

Goslar, Germany. 9-II November 2008

Published: 5 June 2009

Chemistry Central Journal 2009, 3(Suppl I):P42 doi:I0.II86/I752-I53X-3-SI-P42

This abstract is available from: http://www.journal.chemistrycentral.com/content/3/SI/P42

(c) 2009 Kuhn et al; licensee BioMed Central Ltd.

The CDK-Taverna project aims at building an open-source pipelining solution through combination of different open-source projects such as Taverna [1] the Chemistry Development Kit (CDK) [2] and Bioclipse [3].

Pipelining or workflow tools allow for the Lego ${ }^{\mathrm{TM}}$-like, graphical assembly of $\mathrm{I} / \mathrm{O}$ modules and algorithms into a complex workflow which can be easily deployed, modified and tested without the hassle of implementing it into a monolithic application. Current developments in CDKTaverna focus on a soft computing framework which allows a flexible use of different methods from, for example, the WEKA [4] library. Additionally an implementation of the ART2a [5] algorithm is added as worker and could be used for cluster purposes. Worker which analyse and compare the cluster results are also implemented. Pgchem::Tigress [6] a chemoinformatic cartridge for a PostgresSQL database is used to allow the handling of large datasets. Therefore a number of worker for adding, selection and searching molecules from and on the database are added.

\section{References}

I. Oinn T, Addis M, Ferris M, Marvin D, Senger M, Greenwood M, Carver T, Glover K, Pocock M, Wipat A, Li P: Taverna: A tool for the composition and enactment of bioinformatics workflows. Bioinformatics 2004, 20(I 7):3045-3054.

2. Steinbeck $C$, Han YQ, Kuhn S, Horlacher O, Luttmann E, Willighagen E: The Chemistry Development Kit (CDK): An open-source Java library for chemo- and bioinformatics. J Chem Inf Comput Sci 2003, 43:493-500.

3. Spjuth O, Helmus T, Willighagen EL, Kuhn S, Eklund M, et al.: Bioclipse: An open rich client workbench for chemo-and bioinformatics in press.
4. Witten IH, Frank E: Data Mining: Practical machine learning tools and techniques. 2nd edition. Morgen Kaufmann, San Francisco; 2005.

5. Carpenter GA, Grossberg S, Rosen DB: Neural Networks I99|, 4:493.

6. Schmid EG: [http://pgfoundry.org/projects/pgchem/]. 